\title{
Successful endoscopic removal of an eroded gastric ring with subsequent endoscopic suturing of the luminal defect
}

A 50-year-old woman with a history of Fobi Pouch Roux-en-Y gastric bypass (RYGB) presented to our hospital with abdominal pain, reflux, and significant weight loss. Initial endoscopic evaluation at an outside hospital revealed a Silastic ring that had eroded into the gastric pouch. The patient refused surgery and was referred to our institution for management.

On upper endoscopy, there was evidence of a RYGB with an eroded Silastic ring protruding below the gastric pouch into the jejunum. A double-channel gastroscope was used. A rat tooth forceps (Rat Tooth Alligator Jaw Grasping Forceps; Olympus America Inc., Central Valley, Pennsylvania, USA) was deployed through one channel to grasp the ring from the mucosa. The ring was then dissected using endo-scissors (Olympus Endotherapy Loop Cutter; Olympus America Inc.,), which were inserted through the secondary channel. The endoscopic suturing system was used to repair the full-thickness defect created from ring removal. Three interrupted sutures were placed successfully across the gastrojejunal anastomosis, and a clinch was used to ensure closure of the ring defect. Closure was confirmed by lack of extravasation of contrast after injection ( $\triangleright$ Fig. 1, $>$ Video $\mathbf{1}$ ). The procedure was well tolerated, and no adverse events occurred. At 1-month follow-up, the patient reported significant relief of her symptoms.

The Silastic ring is a restrictive band, which is surgically placed around the gastrojejunal anastomosis in patients who have undergone RYGB. The intent is to further limit the size of the gastric pouch in order to achieve weight loss [1]. Possible causes of band erosion include: excessive constriction of the band, suturing the band to the stomach, and infection [2]. Symptomatic band migration or erosion necessitates removal [3].
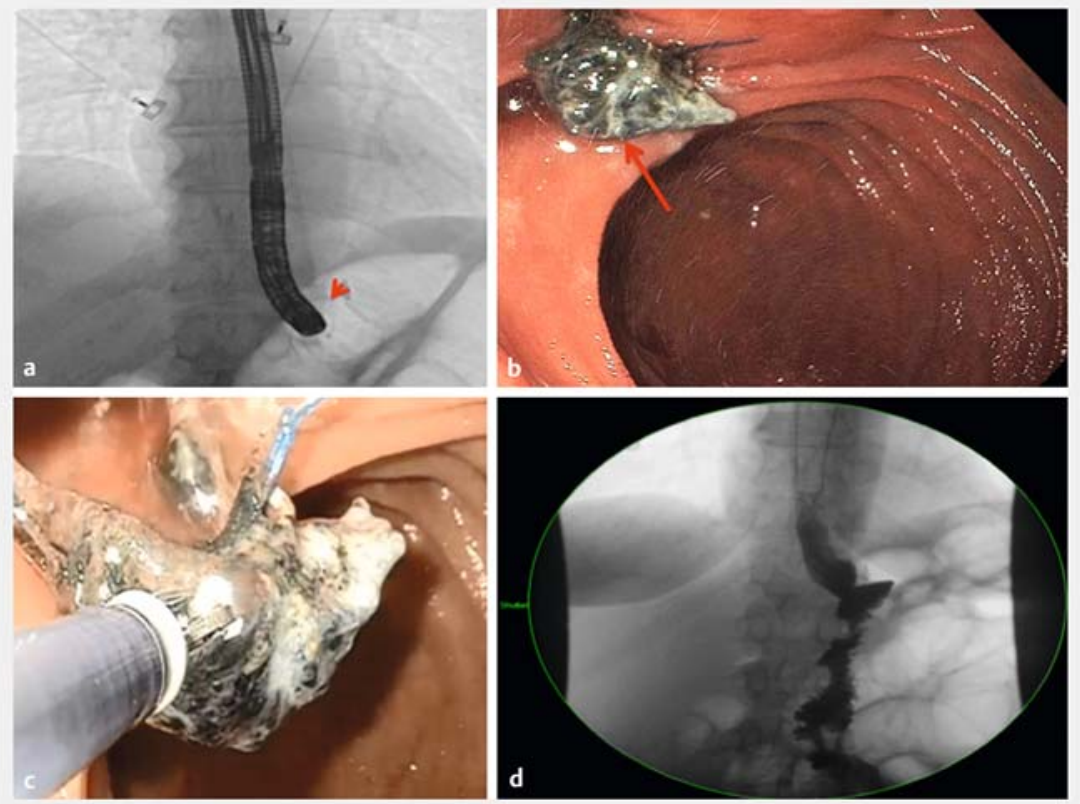

- Fig. 1 Successful endoscopic removal of an eroded gastric ring, with subsequent endoscopic suturing of the luminal defect. a Radiological image of the eroded gastric ring (arrowhead) at the beginning of the procedure. $\mathbf{b}$ The eroded gastric ring (arrow) prior to removal. c Dissected eroded gastric ring being removed using rat-tooth forceps. d Upper gastrointestinal series showed no contrast leak following suturing of the mucosal defect.

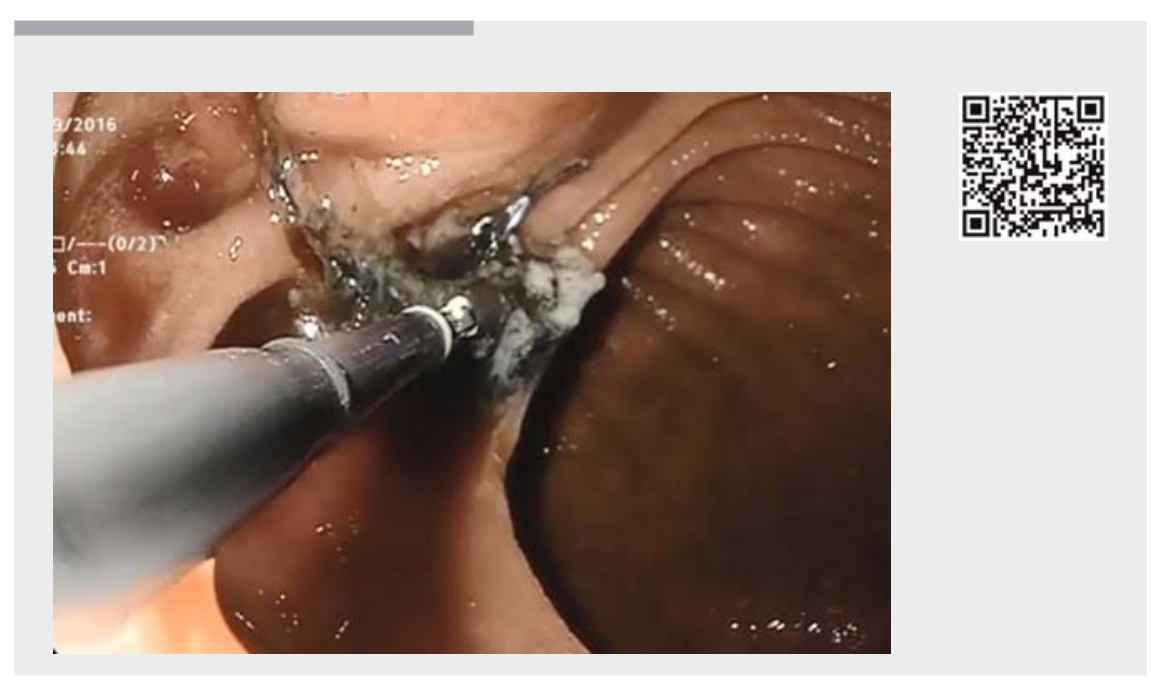

$\checkmark$ Video 1 Successful endoscopic removal of an eroded gastric ring, with subsequent endoscopic suturing of the luminal defect. 
Recently, endoscopy has emerged as the first-line technique for the management of band erosion because of a high rate of technical success, and low rates of morbidity and mortality $[2,4,5]$. This video demonstrates a safe, efficient, and feasible method for treatment of Silastic ring erosion.

Endoscopy_UCTN_Code_TTT_1AO_2AN

\section{Competing interests}

Reem Z. Sharaiha is a consultant for Apollo endosurgery.

The Authors

\section{Enad Dawod ${ }^{1}$, Aleksey Novikov ${ }^{1}$, Najib} Nassani ${ }^{2}$, Ming Ming Xu ${ }^{1}$, Monica Saumoy ${ }^{1}$, Cheguevara Afaneh ${ }^{3}$, Reem Z. Sharaiha ${ }^{1}$

1 Division of Gastroenterology and Hepatology, New York Presbyterian Hospital, Weill Cornell Medical College, New York, New York, United States

2 Department of Medicine, Staten Island University Hospital, Northwell Health, Staten Island, New York, United States

3 Division of Surgery, New York Presbyterian Hospital, Weill Cornell Medical College, New York, New York, United States

\section{Corresponding author}

\section{Reem Z. Sharaiha, MD, MSc}

Division of Gastroenterology \& Hepatology, Department of Medicine, Weill Cornell Medical College, 1305 York Avenue, 4th Floor, New York, NY 10021

Phone: +1-646-962-4000

Fax: +1-646-962-0110

rzs9001@med.cornell.edu

\section{References}

[1] Fobi MA, Lee H. The surgical technique of the Fobi-Pouch operation for obesity (the transected silastic vertical gastric bypass). Obes Surg 1998; 8: $283-288$

[2] Fobi MA, Lee $H$, Igwe $D$ et al. Band erosion: incidence, etiology, management and outcome after banded vertical gastric bypass. Obes Surg 2001; 11: 699-707

[3] Chisholm J, Kitan N, Toouli J et al. Gastric band erosion in 63 cases: endoscopic removal and rebanding evaluated. Obes Surg 2011; 21: $1676-1681$

[4] Neto MP, Ramos AC, Campos JM et al. Endoscopic removal of eroded adjustable gastric band: lessons learned after 5 years and 78 cases. Surg Obes Relat Dis 2010; 6: 423 427

[5] Blero D, Eisendrath P, Vandermeeren A et al. Endoscopic removal of dysfunctioning bands or rings after restrictive bariatric procedures. Gastrointest Endosc 2010; 71: $468-474$
Bibliography

DOI https://doi.org/10.1055/s-0043-106046

Endoscopy 2017; 49: E173-E174

(c) Georg Thieme Verlag KG

Stuttgart · New York

ISSN 0013-726X

\section{ENDOSCOPY E-VIDEOS}

https://eref.thieme.de/e-videos

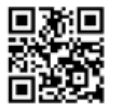

Endoscopy E-Videos is a free access online section, reporting on interesting cases and new techniques in gastroenterological endoscopy. All papers include a high quality video and all contributions are freely accessible online.

This section has its own submission website at https://mc.manuscriptcentral.com/e-videos 